\title{
Quando ainda não existia a palavra: M - o vampiro de Dusseldorf (1931)
}

\section{When the word did not exist yet: "M" (1931)}

https://doi.org/10.34112/2317-0972a2018v36n73p87-103

Nilda Alves ${ }^{1}$

NoAle Toja ${ }^{2}$

RESUMO: Este trabalho provoca a pensar acerca dos processos educativos a partir do envolvimento do cinema como um dispositivo que compõe as redes educativas de docentes e discentes, nos projetos de pesquisa "Redes educativas, fluxos culturais e trabalho docente o caso do cinema, suas imagens e sons" (2012-2017) e "Processos curriculares e movimentos migratórios: os modos como questões sociais se transformam em questões curriculares nas escolas" (2017-2022), desenvolvidos com a criação de cineclubes, esses 'praticantespensantes' das escolas em alguns municípios do Rio de Janeiro. Esses projetos têm como objetivos: identificar os mundos culturais dos docentes, bem como os modos como questões sociais graves entram nos currículos escolares. $\mathrm{O}$ filme em torno do qual se trabalha neste artigo é $M$ - o vampiro de Dusseldorf (1931), do diretor alemão Fritz Lang, exibido em encontros dos cineclubes. Um filme provocativo, inovador para sua época, coloca questões acerca da presença do desvio social em contextos cotidianos e os modos como agem ou podem agir autoridades públicas e 'praticantespensantes' de cotidianos quanto a esta questão.

PalavRAS-chave: Redes educativas; cineclube; currículos.

1. Universidade Estadual do Rio de Janeiro, Rio de Janeiro, RJ, Brasil.

2. Universidade Estadual do Rio de Janeiro, Rio de Janeiro, RJ, Brasil. 
ABSTRACT: This study is an invitation to think about the educational processes that take place with the involvement with cinema as a dispositive that makes up in the educational network of teachers and students, in the research projects "Educational networks, cultural flows and teaching work - the case of the cinema, its images and sounds" (2012-2017) and "Curricular process and migratory movements: the ways how social issues are transformed in curricular issues at school" (2017-2022), developed with the creation of cineclubs, these 'practitionersthinkers' that exist in schools of a few cities in the state of Rio de Janeiro. These projects have, as objectives, identifying the cultural worlds of the teachers, as well as the way how serious social issues affect the school curriculum. The movie we have worked with in this article is "M" - Eine Stadt sucht einen Mörder (1931, Germany), shown in cineclubs meetings. A provocative movie, innovative for its time, it shows us questions about social deviation in everyday life contexts and the way public authorities and the 'practitionersthinkers' may and will deal with them.

KEYWORDS: Educational networks; cineclub; curriculum.

\section{INTRODUÇÃO}

Dentro de projetos em cujo desenvolvimento queríamos compreender aquilo que identificamos como os "mundos culturais dos docentes" e os modos como questões sociais graves se incorporam aos currículos escolares, incrementamos a criação de cineclubes com docentes e discentes em alguns municípios do Rio de Janeiro $^{3}$. As temáticas com que trabalhamos foram, no primeiro projeto, bastante variadas e permitiram 'conversas'4 em torno de questões culturais da contemporaneidade, presentes nos tantos 'dentrofora's das escolas e nos agrupamos em: a) filmes com docentes e discentes que nos permitiram trabalhar vivências urbanas e rurais; questões de trabalho e emprego de professores e professoras; práticas escolares na contemporaneidade em processos de criação; relações entre docentes e discentes (e seus responsáveis) em múltiplos processos curriculares; b) outras temáticas, como diferenças/identidades raciais, incluindo questões religiosas; diferenças/

3. Os municípios nos quais trabalhamos são: Rio de Janeiro, Nova Friburgo, Angra dos Reis, S. Gonçalo e Paracambi.

4. As “conversas' nas pesquisas com os cotidianos são entendidas como o lócus principal de seu desenvolvimento.

5. Nas pesquisas com os cotidianos temos percebido que as dicotomias, necessárias à criação e ao desenvolvimento das ciências na Modernidade, têm significado limites àquilo que precisamos criar e desenvolver nestas pesquisas. Temos assinalado esta questão, escrevendo os termos dessas dicotomias desta maneira: juntos, em itálico e entre aspas simples. 
identidades de gênero; relações com as múltiplas mídias; movimentos sociais em suas reivindicações por escolas. Já no segundo projeto, concentramo-nos em uma questão principal: as migrações humanas, suas origens na história e, especialmente, na contemporaneidade, sempre buscando compreender os movimentos de sua incorporação nos currículos escolares.

Com esta variedade de filmes, buscamos melhor compreender as redes educativas e culturais que os 'praticantespensantes' (OLIVEIRA, 2012) das escolas formam e nas quais se formam e como os contatos que aí estabelecem ajudam a resolver os problemas que enfrentam em seu dia a dia curricular, criando 'conhecimentossignificações' incorporados nos currículos cotidianos. Entendidas como de 'praticasteorias' - já que percebemos que nelas são criadas, permanentemente, práticas necessárias e possíveis ao viver cotidiano e intimamente relacionadas à criação de formas de pensamento a que podemos chamar teorias -, as redes educativas com que estamos trabalhando são assim enunciadas: a da formação acadêmica; a das ações pedagógicas cotidianas; a das políticas de governo; a das ações coletivas dos movimentos sociais; a de criação e "uso" das artes; a das pesquisas em educação; a de produção e 'usos' de mídias; a das vivências nas cidades, no campo e à beira das estradas.

Compreendendo a existência dessas redes e buscando identificá-las tal como se apresentam em filmes; percebendo que os processos de pesquisa que desenvolvíamos exigiam tratar da questão de pessoas consideradas "especiais", em tantos grupos sociais, com as dificuldades que existem para relacionarmo-nos com elas; e considerando o modo como essas relações nos questionam nas escolas, tomamos a decisão de trabalhar com o filme $M-O$ vampiro de Dusseldorf', do diretor alemão Fritz Lang, de 1931, sabendo os desafios que teríamos, pois se tratava de um filme preto e branco, em momento no qual o som $^{8}$ começava no cinema e com uma forma de atuação ainda bastante exagerada, segundo os cânones atuais. Mas achamos que valia lançarmo-nos a discutir esta questão com um filme que tratava de um serial killer, tal como os chamamos hoje, tendo em especial as séries de televisão americanas nos dado as "chaves-clichês" para os identificar. Ou seja, a partir de um

6. Nas pesquisas com os cotidianos, fomos entendendo que a todo conhecimento criado são criadas para eles significações que os explicam como necessários e, mesmo, justificam sua criação e permanência social.

7. O filme está acessível em: <https://www.youtube.com/watch?v=rgRLbwkVPoA >.

8. Nos projetos desenvolvidos temos tido um apoio importante do músico e criador de trilhas sonoras para o cinema e a televisão, Fernando Moura. Ver Moura (2017). 
filme considerado um dos grandes clássicos do cinema, que trata da questão, relacionando-a a situações sociais contextuais e trazendo inovações técnicas importantes.

M - o VAMPiro De DUSSELDorF - o FILME

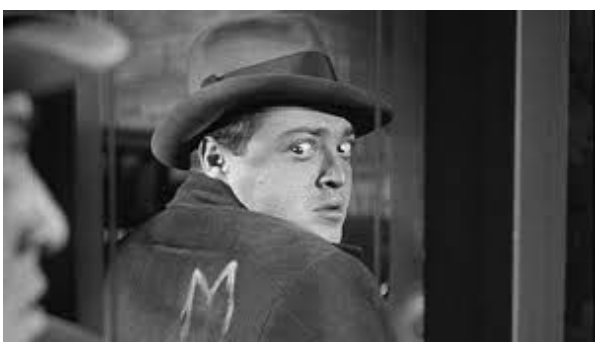

Figura o1. Cena do filme $M$, o vampiro de Dusseldorf que, entre outras, serviu de base ao cartaz mundialmente usado.

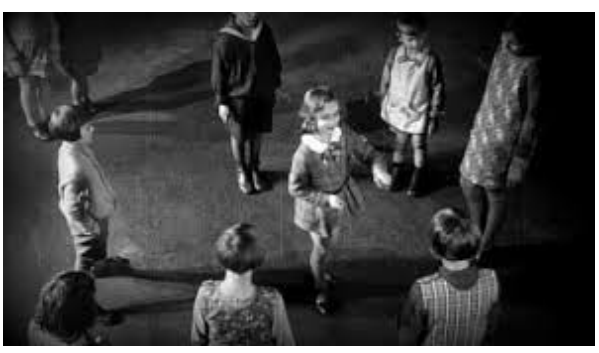

Figura 02. Cena inicial do filme: a menina Elsie, no pátio da escola, brincando

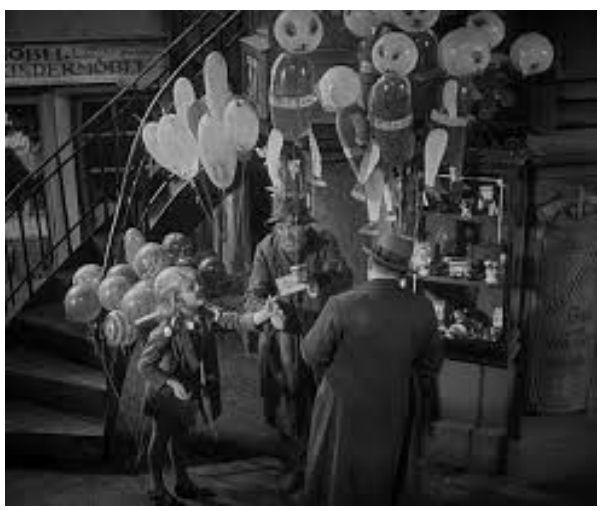

Figura 03. Cena de Beckert comprando balão para Elsie. 
O filme $M$ - o vampiro de Dusseldorf ( $M$ - Eine Stadt sucht einen Mörder), produzido em 1931, é considerado um clássico do cinema expressionista alemão e teve como seu diretor Fritz Lang, cineasta já consagrado quando o produziu. Em síntese, o filme mostra um misterioso infanticida que leva o terror a Dusseldorf, cidade alemã. Como a polícia local não consegue capturar o serial killer, um grupo de foras da lei se une para encontrar o assassino. E, quando o capturam, fazem o seu julgamento segundo as normas dos tribunais que tão bem conhecem.

O filme mostra, de forma criativa e crítica, a história de Peter Kürten, um assassino e violador de mulheres, acontecimento que marcou a década de 1920, na cidade de Dusseldorf. Esse caso causou impactos na Alemanha, repercutiu em outros países e gerou estudos sobre a mente humana, as questões da psicopatia e das relações e das redes sociais envolvidas em comportamentos e ações dessa natureza. Como, por exemplo, fez Karl Berg, que publicou um livro a partir de entrevista realizada com Kürten na prisão. Uma história de vida marcada por diferentes violências sofridas desde a infância possivelmente tenha gerado o sentimento e o comportamento violento em Kürten, que ainda criança matou dois amigos afogados em um rio. Kürten foi executado em 02 de julho de 1931, em Colônia, Alemanha, quase dois meses após o lançamento do filme $M$.

Embora diversos críticos do filme, desde sempre, digam que também nesta obra Fritz Lang faz uma crítica às mazelas da sociedade moderna e mesmo ao regime político que se instalava na Alemanha naquele momento, na biografia do diretor há a informação de que Hitler, ao assistir a película Metrópole, produção anterior de Lang, ficou fascinado com a qualidade e a abordagem de seu conteúdo e convidou-o, juntamente com sua esposa, Thea Von Harbou, para incumbir-se da campanha publicitária do partido nazista. Parece que se, em um primeiro momento, os dois aceitaram o convite, após o filme de que estamos tratando, Lang se distanciou desse grupo e quase imediatamente fugiu para Paris'. Importante lembrar que o título inicial do filme era Os assassinos estão entre nós, que teria sido censurado por agentes do governo alemão, à época.

A existência de uma "organização criminosa" que dá solução ao problema, a atmosfera pesada, o ritmo denso do filme, com os inúmeros recursos audiovisuais incorporados, consegue captar as agruras e as incertezas dos contextos

9. Ele foi em seguida para os Estados Unidos, onde não consegue seguir sua importante carreira anterior. Ele trabalhou em um dos clássicos do cinema, Sunset boulevard, no qual faz o papel de mordomo. 
políticos, sociais e econômicos daquela época, o que é, aliás, típico da composição expressionista.

Entre outras ações, para se aproximar - e retratá-las - das questões que envolvem o sofrimento psiquiátrico e a violência que ele pode provocar - tônicas do filme -, Lang ficou internado num manicômio por uma semana, estudou vários processos judiciais de crimes ligados a psicopatia, estudou o comportamento das pessoas em situação de surto e em julgamentos de crimes dessa natureza, o que o levou a preparar a cena belíssima do vilão Hans Beckert ${ }^{10}$, no momento do julgamento, nos últimos 20 minutos da película. Nela, Beckert evidencia sua fragilidade, seu medo e reconhece sua humanidade, quando fala de sua falta de controle sobre os seus atos, como se um outro ser o tomasse. São quatros minutos de um discurso que começa questionando os inquisidores e a validade daquele julgamento, questionando os que estão presentes na cena: "O que você sabe sobre isso? Quemévocê, afinal? Quem são vocês? Criminosos? Todos criminosos? Arrombam cofres, assaltam casa, batem carteira, mas poderiam ter sido outras coisas, se alguém lhes tivessem ensinado a trabalhar, e se vocês não fossem um bando de bastardos e preguiçosos. Mas não posso ajudar a mim mesmo, não tenho controle sobre isto [...]". Nesta longa fala, está contida a posição de Lang acerca desses seres e as relações potentes que fazem com a sociedade em que vivem e aparecem, cometendo seus crimes.

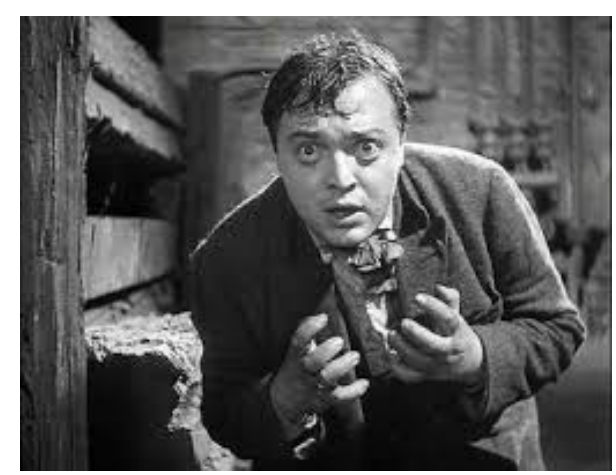

Figura 04. "Quero escapar, quero fugir de mim mesmo, mas é impossível. ... Sou possuído por fantasma, fantasma de mães. E das crianças, elas nunca me deixam. ... Eu não consigo lembrar de nada. ... Mas quem irá me acreditar? Quem sabe o que é isto para mim?" (Beckert,

$$
1: 43: 30-1: 44: 58) \text {. }
$$

10. Representado pelo magnífico ator de teatro e cinema austríaco, Peter Lorre. De origem judia, ele fugiu para os Estados Unidos antes mesmo de Lang, que também era meio judeu. Nos EUA, Lorre trabalhou no conhecidíssimo Casablanca e também em Relíquia macabra e Cassino Royale. 
Este julgamento se dá porque são os "fora da lei" que conseguem capturar o assassino, pois a polícia e as autoridades em geral ficam tontas com o que está acontecendo. Aos 36 minutos do filme, Lang mostra isso, com a polícia justificando sua incompetência ao resolver o caso, falando da sua complexidade, pela forma como as crianças desaparecem sem deixar rastro, ao mesmo tempo que legitima a astúcia do vilão, que, segundo os policiais, não deixa pistas. E para se eximirem da responsabilidade pela demora em solucionar os crimes, ainda responsabilizam os pais pela falta de cuidado, que leva ao sumiço das crianças.

No processo de investigação policial, o filme mostra a fragilidade do sistema de segurança, que não consegue criar um plano de ação que leve ao objetivo intentado. E, ao contrário, cria pânico na cidade, ao colocar qualquer pessoa como suspeito. $\mathrm{Na}$ busca pelo assassino, há cenas que mostram a invasão das casas de pessoas humildes, a prisão de um idoso que é abordado por uma criança que lhe pergunta a hora etc. Essas ações buscam, não resolver o problema, mas achar um "bode expiatório". Ë nesse momento de confusão que o primeiro título do filme, censurado, é dito três vezes, nervosamente: "o assassino está entre nós". Toda essa sequência traz uma incrível ambiência sonora, acentuando o nervosismo da situação e o estado caótico das buscas efetuadas. Esta sequência é cortada para cenas nas quais é lida a carta escrita pelo assassino, encaminhada e publicada por um jornal local. Para esta cena, Lang traz o recurso do silêncio, utilizado também em outros momentos, com outras intenções.

O diretor do filme prepara um jogo de cena, tecendo duas tramas paralelas - na busca da solução dos crimes e na captura do assassino. De um lado, autoridades da segurança pública e, de outro, os criminosos. Os pontos de interseção entre as duas situações estão na repetição de frases com entonações diferentes, ou como resposta à última deixa, ou ainda com alternativas contrárias. Um exemplo do uso desses recursos é a transição de uma cena para outra, usando a relação de tempo de investigação, "são oito meses que a polícia está no caso", frase enfatizada por um dos agentes de segurança. Na cena seguinte, no grupo de criminosos, a mesma frase é repetida, embora com outra entonação. No final da sequência, os criminosos decidem que vão resolver o caso e pedem a colaboração de uma parcela da população, ao contrário dos agentes de segurança, que se queixam da participação popular: para eles o povo não colabora, só sabe cobrar. A tática usada pelos criminosos será recrutar os mendigos e os trabalhadores pobres da cidade, mapeando seus pontos de permanência no espaço. Esses personagens, que já circulam cotidianamente nos espaços, serão os observadores de movimentos de sujeitos, sob qualquer suspeita. 
Usam para isso um homem que toca realejo e é surdo, bem como um cego que vende balões de gás hélio (ver imagem 3 ). Entendem que o assassino não irá suspeitar dessas pessoas. Com isso, o diretor questiona os "conhecimentosignificações" e o poder, sobre a cidade, daqueles que a habitam de modos tão diferentes.

Mas não só neste momento a tensão se instala. Também quando a imensa turba de bandidos assume o papel da justiça - com amplo conhecimento de como ela trabalha -, Lang provoca um pensamento acerca das intenções de sistemas políticos que engendram as vidas e os corpos sociais. Mais ainda, quando traz a atuação da polícia sobre a resolução do crime, mostrando ações de chantagem e corrupção na manutenção de um sistema.

Em $M$, Fritz Lang inaugura o som na cinematografia, com um requinte nos modos de estar presente, que, para sua época e por ser um pioneiro, revela a sensibilidade humana na introdução do áudio na complexidade da tessitura narrativa, compondo a dramaticidade da obra. Assim como pelas opções estéticas no que é feito imagem, nos sons o autor ressalta seus argumentos com silêncios, pequenos barulhos cotidianos a cantiga das crianças, o barulho da bola, o som de utensílios domésticos, buzinas de carros -, até o assobio do assassino quando procura sua vítima e acaba por identificá-la.

A particularidade da trilha sonora em $M$ são as marcações de tensionamento, criando padrões sonoros para cada situação. Sirenes e apitos que marcam um intervalo de tempo, que anunciam um próximo acontecimento na obscuridade de um futuro, levando ao suspense. A marcação do relógio cuco para indicar uma rotina e uma espera, com o receio do inesperado que naquela situação crítica pode acontecer, quando a mãe refaz o ritual de arrumar a mesa de refeição, esperando a filha que não vai chegar. O som do cuco é prolongado pelo som de buzinas, mostrando que algo irá acontecer. É a filha que volta da escola e, na sua inocência, joga a bola contra o cartaz que anuncia uma recompensa para quem denunciar o vilão, que a fará sua próxima vítima. 

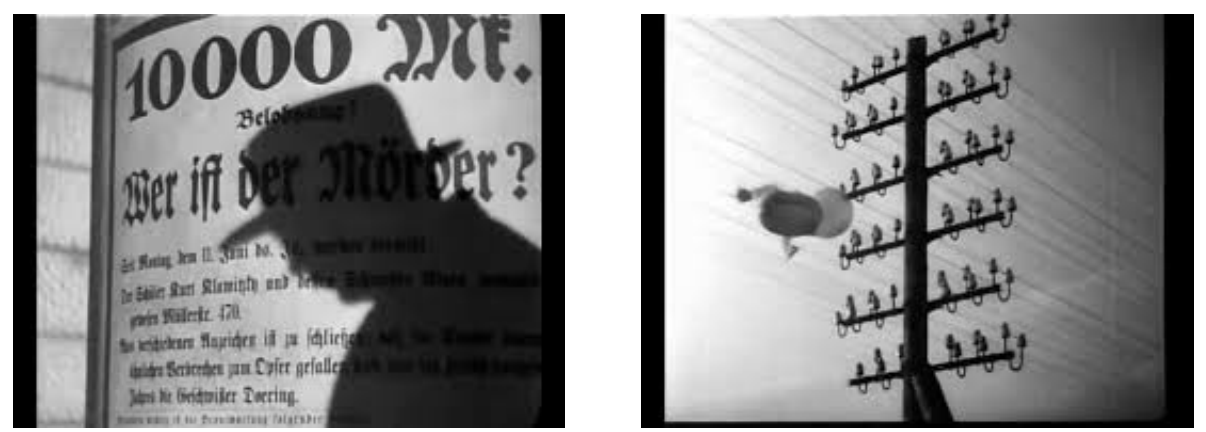

Figuras 05 e 06. Cenas do cartaz oferecendo recompensa, com a sombra do assassino, e o balão preso na rede de alta tensão.
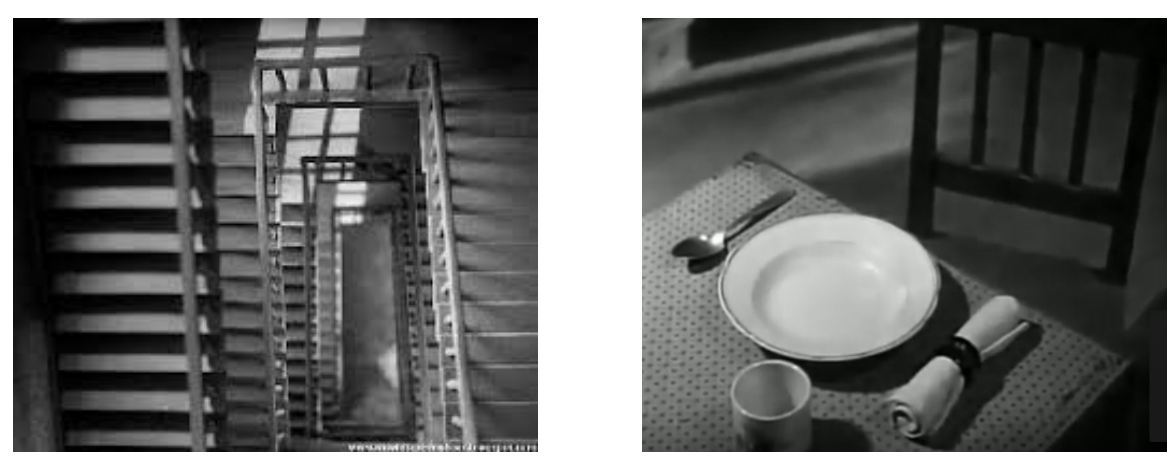

Figuras 07 e 08 . As escadas vazias e o prato vazio mostrando a ausência da filha que não chega.

Os silêncios agudizam ainda mais a demora e a ausência, mostrando o labirinto da escada num plano de cima para baixo, o pátio vazio, 'vestido' com as poucas roupas penduradas, a mesa posta com prato e cadeira vazia, com rastros da voz da mãe no seu desespero; como revelará na cena seguinte numa montagem de paralelos, um silêncio do vazio na bola que rola num jardim, num balão que se prende, se debate na rede de alta tensão e se solta para outra dimensão. É o enunciado do feito do malfeitor. Na tensão dos silêncios, entra a voz fria de quem anuncia a edição extra, trazendo a notícia de um novo crime.

$\mathrm{O}$ assobio do assassino quando busca a nova vítima, uma das marcas sonoras no filme, é de três tipos: o assobio máster, que é o registro do assassino, com a música retirada da peça teatral Peer Gynt, Suíte I Op. 46, última parte de "O castelo do rei”, do compositor norueguês Edvard Grieg (1843-1907); o assobio de um dos policiais analisando os documentos de um dos suspeitos, que estava numa casa de 
prostituição, indica uma falsa cumplicidade entre o agente e o suspeito; e o terceiro é o assobio dos criminosos para sinalizar as condições de segurança do lugar onde vão capturar o assassino e durante o seu julgamento.

TÁticas e ASTÚCIAS NA INVESTIDA DE CAPTURA DO ASSASSINO

Tática é a arte do fraco

(CERTEAU, 2017)

Reunir os mendigos que buscam um assassino de crianças vai criar táticas indicadas pelas possibilidades de viver e criar realidades dentro da cidade: colocar um surdo tocador de realejo no centro de uma praça para atrair as crianças e os supostos suspeitos; colocar um falso cego pedindo esmola para ficar atento aos homens que acompanham crianças; ter um vendedor de balas perneta junto a uma vitrine, observando o movimento da rua; colocar um cocho do outro lado da rua, observando a movimentação das crianças. Por que usar só os ditos inválidos? Qual a provocação que Lang pretende fazer, ao dar ênfase a uma população underground? Quais são as astúcias impregnadas nesse fazer dos usos de habilidades criadas nas vivências cotidianas de uma cidade? Numa perspectiva certeauniana, observar a apropriação desses dispositivos de linguagem corporal, comportamentos e fazeres sociais numa direção de deslocamento do lugar comum é criar um campo de potências que está na capacidade inventiva do acontecimento, pois refere-se aos modos de agir criativamente nos cotidianos e em suas redes. Os mendigos usam de suas astúcias cotidianas para criar uma rede de mapeamento de comportamentos de crianças e adultos. Eles se colocam na cidade como seres em observação, aparentemente desprovidos de sentido, porque não são coerentes com o espaço construído, escrito e pré-fabricado onde se movimentam (CERTEAU, 2017, p. 91), mas aí estão. Os mendigos como objetos deslocados, posicionados taticamente, permanecem vigilantes diante das falhas que as conjunturas particulares vão abrindo na vigilância do poder proprietário. Aí ele vai caçar. Cria ali surpresas, consegue estar onde ninguém espera. É a astúcia (CERTEAU, 2017, p. 95). Quando Beckert está de posse de sua última vítima, os mendigos estão todos a postos, acompanhando cada passo, cada movimento. Um deles escreve um " $\mathrm{M}$ " em uma das mãos e carimba as costas de Beckert, assim ninguém mais o perde de vista. Cria-se uma rede de informações, na qual vão atualizando toda a movimentação do assassino e de sua vítima. Até que a 
menina, ao sair da loja de brinquedos, vê a sujeira no paletó do sujeito e a indica a Beckert que, nesse momento, desconfia que está sendo observado, perde sua presa e foge, numa sequência de assobios emitidos pelos mendigos com a intenção de comunicar a fuga e indicar as direções tomadas pelo assassino. Os assobios dos mendigos nesse momento passam a ser um recurso usado para sinalizar os pontos de fuga e as direções tomadas por Beckert, eles vão tensionando a cena, mostrando a angústia do assassino, ao se ver encurralado numa rua vazia, apenas com os mendigos o cercando na entrada de um prédio, quando é usado o som da buzina de carros cortando a cena e permitindo a entrada do vilão no prédio, fazendo com que os mendigos o percam de vista, criando mais suspense para a cena.

BECKERT, UMA PESSOA ESPECIAL?

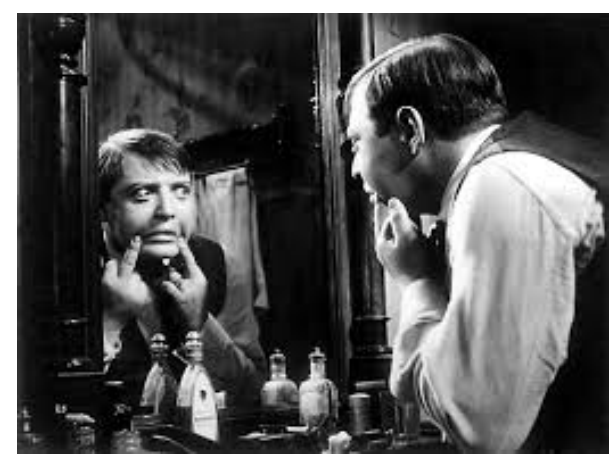

Figura 09. Cena durante a análise da carta escrita por Beckert.

Beckert, ao andar pela cidade, para diante de uma banca de frutas, come uma, contempla uma vitrine, se mostra como uma pessoa comum, inofensiva, até o momento em que aparece uma criança refletida na vitrine. 

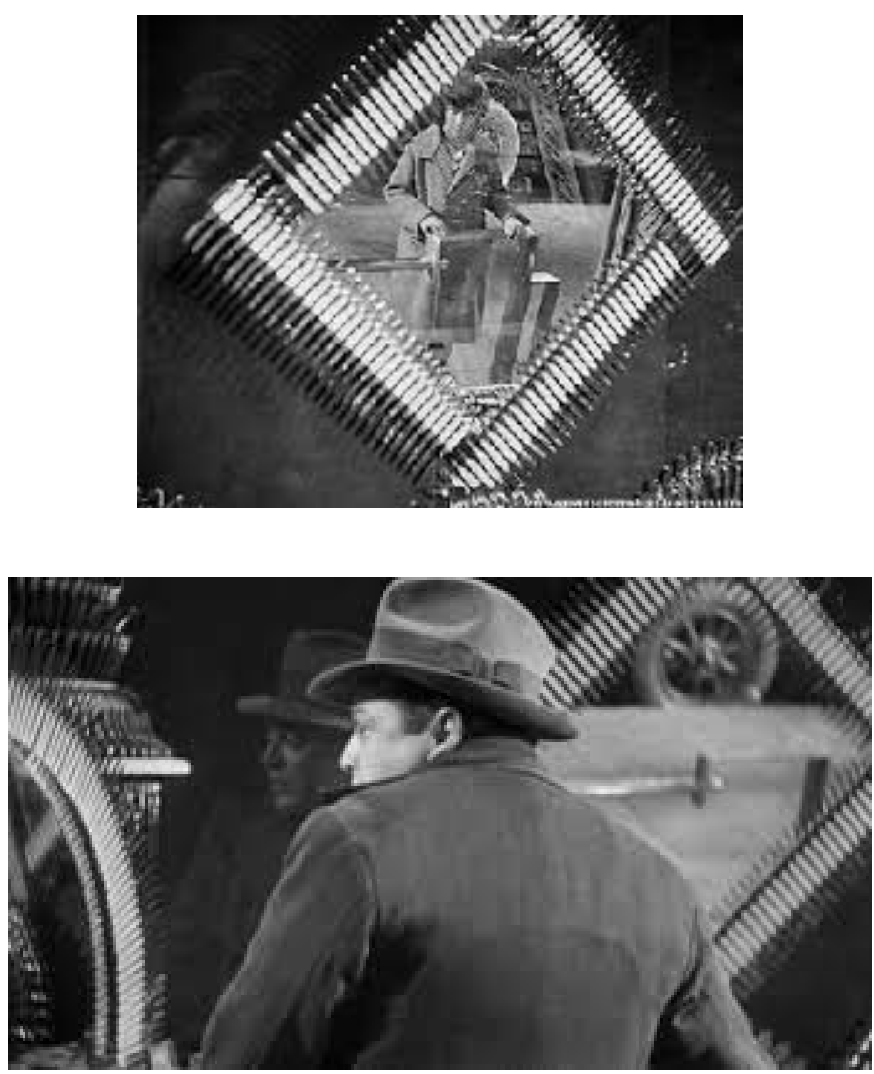

Figuras 10 e 11. Cena da mudança de comportamento de Beckert, ao ver a menina.

É nítida a transformação do personagem. Ele vai ficando desconcertado, seu transtorno vai se evidenciando, seus olhos vão ficando lânguidos, sua respiração se altera, a menina sai do seu foco e as buzinas começam a anunciar o perigo, o corpo em posição de caça, e Beckert parte para o ataque, entoando seu assobio. A buzina reforça que o perigo está ao lado. Entra o silêncio, mostrando a desproteção da menina, alheia ao perigo, encantada com a vitrine, que por sua vez apresenta um alvo e uma seta em posições distintas, mas em movimento, indicando uma presa junto do seu predador. A menina parece perceber o perigo, ao passo que o assobio se intensifica, levando ao êxtase, cortado pelo momento em que a menina encontra sua a mãe. $\mathrm{O}$ assobio para, e a frustração é nítida no rosto e no corpo de Beckert. Ele se senta à mesa, atrás de plantas que cercam um bar, e pede um café, desiste e pede um vermute e passa para um conhaque - até esse instante, no filme, ainda não se tinha ouvido sua voz. Os 
acontecimentos vão alterando o estado de humor do personagem. Ele recupera sua calma, voltando a assobiar, em busca de uma próxima vítima. $\mathrm{O}$ mendigo cego que vende balão reconhece o assobio, é o mesmo do desaparecimento da menina Elsie. Desta vez, Beckert não parou com sua vítima para comprar o balão, nem sequer passou perto, mas a cegueira do vendedor de balões permitiu que sua escuta aguçada o identificasse. $O$ vendedor cego do balão pede ajuda a outros para detê-lo, um deles vem ao seu encontro e consegue ver Beckert com a menina. Lang, o diretor, reforçando sua astúcia no uso do som, coloca alguém que não enxerga para reconhecer o vilão, o que inicia a rede de comunicação entre os mendigos que vão capturar Beckert.

O personagem pouco revela de sua psicopatia até este momento, e é se vendo perseguido que sua doença aparece: inicialmente, ele caminha, tranquilamente, com a menina pela rua; entra numa loja de doces, onde deixa a menina escolher à vontade o que deseja, não sendo observado nem pela vendedora, que de nada desconfia - é um homem sereno, bem vestido, com uma menina comprando balas, quem suspeitaria? No entanto, na rede de mendigos já armada, um deles observa pela vidraça da loja e já se comunica com um outro. Beckert sai da loja com a mesma tranquilidade, a menina agradece o doce, eles param no meio da rua- a câmera corta para o bolso de Beckert, ele puxa um canivete, um indício do que está por vir. Mas um dos mendigos está atento ao movimento. Beckert quebra a tensão, descascando uma fruta com naturalidade, a menina está absorta, o mendigo aproveita este momento e escreve com giz em sua mão o "M" com que vai marcar as costas de Beckert, falando que ele é uma ameaça para a cidade, porque está sujando a rua com as cascas de fruta. Beckert leva um susto, começa a ter um leve sinal de desequilíbrio emocional, pois alguém o tocou. Se recompõe e, mantendo seu ritual, vai à loja de brinquedos para agradar a menina. Quando saem, na porta da loja, a menina mostra o que está em suas costas. É no momento em que vê a marca - e se percebe perseguido - que seu rosto e seu corpo se transformam e ele inicia sua fuga. De predador passa a presa. Acuado, tem uma expressão de pavor, e sua respiração é ofegante. $O$ prédio onde se refugia é invadido pelos criminosos determinados a capturá-lo. Seu medo cresce, sua expressão assume um aspecto infantil.

Na perseguição pelo prédio, Lang traz mais uma vez o som para comunicar as ações: um assobio que indica que a área está limpa, uma escuta de uma batida que denuncia que existe alguém escondido, tilintar de chaves que indica que outro se aproxima, criando uma tensão entre os personagens. 
Lang cuidou na escolha do ator Peter Lorre, com características peculiares, com seus olhos grandes e estufados, ora esbugalhados, tipo físico bonachão. Quando acuado, em condição de vulnerabilidade, o coloca como uma criança abandonada. Ele não sabe quem o persegue exatamente, e seu corpo e rosto mostram isto: podem ser os policiais, os criminosos, as mães, os mendigos, os homens da cidade, as crianças, os assobios, as buzinas, o cuco, as balas, o balão, o atrito entre o controle e o não controle, as vozes que povoam os ouvidos; são atravessamentos no processo de subjetivação de Beckert. Quando, após capturado, vai ao julgamento diante dos criminosos, o desespero toma seu corpo: como um bebê chorão, pede clemência e diz que é um engano, que não tem nada a ver com o que aconteceu. Mas é interrompido pela voz do cego, o que faz mudar seu semblante para uma expressão de pavor, pois o cego é a primeira testemunha do crime. Quando percebe que não tem mais saída, busca a fuga dentro do medo e revela-se na sua humanidade diante do ódio da plateia que quer sua morte. O que está em julgamento é o mal que foi feito àquelas pessoas que estão presentes, não mais às crianças. É a necessidade de banir um verme, limpar a sociedade. Todos se encontram na condição de juízes racionais, empregando a máxima: "Olho por olho, dente por dente". Fritz Lang nos provoca com essa reflexão: quem somos nós para julgar? O que conhecemos do outro para julgar? Argumentos, aliás, usados no filme pelo personagem que interpreta, entre os bandidos, no julgamento, o papel de defensor do réu, que lembra a um dos juízes que ele é procurado por três homicídios. Na defesa que faz, ele diz:

[...] este impulso que o leva a matar prova sua inocência. [... ] Esta obsessão tornou meu cliente um irresponsável. [...] Ninguém pode punir um irresponsável. [...] Digo que este homem está doente e não deve ser entregue a um carrasco, mas sim a um médico. Ninguém vai matar um homem que não é responsável por seus atos (1:46:06 - 1:47:11).

Mas a condenação é dada, pois os criminosos conhecem bem as leis e suas consequências, sabendo das artimanhas da justiça oficial. Sabem que Beckert pode ser considerado um louco e ficar num manicômio judiciário, detido por algum tempo, mas pode voltar às ruas e cometer novamente suas atividades criminosas. Por isso é importante cortar o mal pela raiz. 
PARA ALÉM DE um Juízo Final

Trazer filmes para os 'espaçostempos' educativos mobiliza sentimentos, pensamentos, cria 'conhecimentosignificações', discute o já conhecido, permite 'conversas'. Toda disputa entre os entendimentos - e desentendimentos - de autoridades e criminosos na solução do crime, no filme, mostra como os interesses, as condições de afetos, as contradições humanas, os julgamentos, os clichês permeiam nossos fazeres cotidianos e as redes que com eles formamos e que nos formam. Como nos vestimos e despimos de nossos papéis sociais, culturais, individuais e coletivos? Que usos fazemos desses papéise que intenções temos em cada atuação? Como julgamos as relações de responsabilidade e irresponsabilidade nos nossos processos educativos? Onde residem a ingenuidade e a malícia? Como lidamos com os controles das emoções, dos corpos, das disciplinas?

Lang recupera esses questionamentos no final do filme, quando, em nome da lei, leva Beckert ao julgamento oficial e ouve uma das mães como a voz do povo. Ela diz que aquilo não trará as crianças de volta e reforça: "Nós, também, então vamos tomar conta de nossas crianças". Lang urde um tecido de responsabilidades na relação do cuidar do outro, que nos leva a pensar: Como estabelecemos nossas redes de cuidados com nossas crianças nos processos educativos? Como cuidamos das diferenças nessas redes? Quais são nossas responsabilidades como docentes e como seres humanos - mulheres, homens, crianças, mães, pais?

No ato em que a defesa, no tribunal dos criminosos, diz que é preciso entregar o réu à polícia, Lang lança mão de sua última cartada, costurando, com a mesma frase, a transição da cena do julgamento e a entrada da polícia desmantelando aquele tribunal e recolhendo o réu para justiça oficial. Esta sequência é entrecortada pelo agudo assobio e pela frase, dando duplo significado: "para a polícia”.

Por fim, ressaltamos a passagem da crise ética sofrida pelo criminoso que foi pego pela polícia, tendo que denunciar e revelar o lugar onde se realizava o julgamento. Ele diz: "Por que logo eu?". Por que logo ele ter que entregar os comparsas e dizer onde Beckert estava? Quantos vampiros há nessa trama? Quantos de nós somos vampiros nas nossas redes de educação, no julgamento do outro? Quantos de nós nos colocamos em contato com nossa humanidade, como faz Beckert em seu juízo final? Como se prender e se desprender das redes de alta tensão nos 'fazerespensares' cotidianos? Como encontrar outras dimensões em processos educativos? 
Questionamentos como estes aparecem nas 'conversas' desenvolvidas com os docentes e os discentes em nossos cineclubes. Por isso, trazer o cinema e as artes, em geral, promovendo 'conversas' com elas para os 'espaçostempos' educativos, tem se mostrado um caminho interessante e criativo para que, com os docentes e os discentes, possamos ir além dos clichês - no cinema ou nos processos curriculares - pensando e agindo juntos.

\section{REFERÊNCIAS}

CERTEAU, M. A invenção do cotidiano - a arte do fazer. Petrópolis: Vozes, 2017.

LANG, F. (Diretor). M, o vampiro de Dusseldorf. Disponível em: <https://www.youtube.com/ watch?v=r9RLbwkVPoA>. Acesso em: 05 abr. 2018.

MOURA, Fernando. Trilhas sonoras - entre o mundo encantado e a vida real. Rio de Janeiro: Música \& Tecnologias, 2017.

OLIVEIRA, Inês Barbosa de. Currículos e pesquisas com os cotidianos: o caráter emancipatório dos currículos 'pensadospraticados' pelos 'praticantespensantes' dos cotidianos das escolas. In: FERRAÇO, Carlos Eduardo; CARVALHO, Janete Magalhães (Org.). Currículos, pesquisas, conhecimentos e produção de subjetividades. Petrópolis: DP et Alli, 2012. p. 47-70.

\section{SOBRE AS AUTORAS}

Nilda Alves é graduada em Geografia (Universidade do Brasil) e em Pedagogia (Universidade Santa Úrsula), com Doutorado em Ciências da Educação (Université Paris Descartes, Paris V, França) e Pós-Doutorado em Educação (Institut Nacional de Recherche Pédagogique, INRP, França). É professora titular da Universidade do Estado do Rio de Janeiro, orienta mestrandos e doutorandos no Programa de Pós-graduação em Educação (ProPEd) na Faculdade de Educação/UERJ-Maracanã/RJ e no PPGEDU - Educação - Processos formativos e desigualdades sociais, na Faculdade de Formação de Professores (FFP)/UERJ-S. Gonçalo/RJ. É líder do GRPESQ (Currículos, redes educativas e imagens. Membro-fundador do Laboratório Educação e Imagem): www. lab-eduimagem.pro.br)/UERJ.

E-mail: nildag.alves@gmail.com.

Noale Toja é graduada em Pedagogia e tem Mestrado em Educação-CulturaComunicação em Periferias Urbanas (ambos pela Universidade do Estado do 
Rio de Janeiro). É doutoranda no Programa de Pós-graduação em Educação (ProPEd)/UERJ), na Linha "Cotidianos, redes educativas e processos culturais" e no GRPESQ Currículos, redes educativas e imagens. É membro do Laboratório Educação e Imagem (www.lab-eduimagem.pro.br)/UERJ. É coordenadora do Kabum! Lab - Laboratório de Cultura Digital - Centro de Criação de Imagem Popular (CECIP).

E-mail: noaletoja22@gmail.com.

Recebido em 27 de janeiro de 2018 e aprovado em 22 de março de 2018. 